\title{
Supporting Teachers to Plan Culturally Contextualized Learning Activities
}

\author{
Ap. Fabiano Pinatti de Carvalho, Junia C. Anacleto, Vania P. de Almeida \\ Neris \\ Advanced Interaction Laboratory (LIA) \\ Department of Computing - Federal University of São Carlos (DC/UFSCar) \\ Rod Washington Luis, Km 235 - São Carlos - SP - 13565-905 \\ \{fabiano, junia, vania\}@dc.ufscar.br \\ +55163351-8618
}

\begin{abstract}
This paper presents PACO-T, a common sense-aided computational tool that helps teachers on planning culturally contextualized learning activities supported by common sense knowledge. The tool is based on the framework PACO, a seven-step framework for planning learning activities that concerns pedagogical issues, for an effective learning. It implements the framework seven steps and makes available common sense knowledge from the Brazilian Open Mind Common Sense (OMCS-Br) knowledge base, so that teachers can analyze how people with the same profile of their target group talk about themes related to the learning activity which is being planned, and therefore possibly identify the target group's previous knowledge and contextualize the learning activity to its needs. In this way teachers can approach themes which they consider relevant to reach the intended pedagogical goals with that specific target group.
\end{abstract}

\section{Introduction}

In order to reach effective learning, it is important to take into account pedagogical issues during the planning of learning activities with the purpose of offering learners conditions to build and acquire new knowledge. Concerning Learning Theories of renowned authors, it can be noticed the importance of contextualizing learning activities to the target group's previous knowledge in order to make possible knowledge retention [4]. Here it is considered as target group the learners who participate of the learning activity or the members of the social group with whom the learners are going to interact in order to apply the knowledge acquired during the learning activity.

Although several authors, such as [3] and [6], mentioned the importance of considering the learning activity target group previous knowledge in the learning 
process, until early 2006, it was not possible to find in the literature how teachers could assess it easily. However, recent researches have shown that common sense knowledge, i.e. the knowledge people acquire since their childhood, considered as truth in the cultural environment where they are inserted into, can be used to state the target group's previous knowledge and to identify its needs [4] [5] [2]. Therefore, we have been investigating how computational technology can make possible the use of common sense to plan learning activity, taking into account the importance of contextualizing the learning activity to the target group's needs in order to reach pedagogical issues. As common sense knowledge expresses cultural knowledge [1], it is considered that learning activities planned based on it is culturally contextualized.

The paper is organized as follows: section 2 presents PACO, the framework for planning learning activities which PACO-T is based on; section 3 presents PACO-T; finally, section 4 presents some conclusion remarks and points to future works.

\section{The Framework PACO and Common Sense}

PACO is a framework designed to support teachers on the Planning of Learning Activities supported by COmputers, which is composed by seven steps [8]: (1) define the learning activity theme, target public and general goal; (2) organize the learning activity topics; (3) choose a pedagogical/methodological reference; (4) plan the learning tasks; (5) choose computer tools to support the tasks execution; (6) edit the learning objects which are going to be used in the learning activity; (7) test pedagogical and technological issues.

PACO has already been used by teachers from different areas such as computer science, nursing and occupational therapy. One of the learning activities planned by nursing professionals using PACO was specially proposed to analyze the possibility of using common sense knowledge during the planning of learning activities, in order to contextualize them to the target group's needs. For details on the case study that show how common sense knowledge can help teachers answer questions which they face with along the framework seven steps so that they can contextualize the learning activity planning to their target group needs see [4] and [5].

\section{PACO-T}

Based on the requirements elicitation performed during the planning of the case study learning activity, it was possible to design PACO-T. This tool maps the questions which teachers should answer during the planning of a learning activity, according to PACO proposal, and offers teachers access to the common sense knowledge stored in the OMCS-Br knowledge base, so that teachers can use common sense as it was previously discussed. For this purpose, the tool uses the semantic networks and the API (Application Program Interface) provided by OMCS-Br.

PACO-T has seven steps, as the framework on which it is based, which should be performed in order to get a learning activity planned. The first thing that should be done in PACO-T when a new learning activity planning starts is to define the learning activity target group's profile and, consequently, tell the system to which ConceptNet it should connect. ConceptNet is the name given to the semantic networks of OMCS projects. This name was first used in the American OMCS project [7] and later it was 
adopted by OMCS-Br [1]. Both projects adopt semantic networks to represent the knowledge collected in natural language in the project web site.

In OMCS-Br, there are several ConceptNets. This is because the Brazilian project offers the possibility of generating a ConceptNet to each combination of the profile parameters (age group, gender, geographical location and education level), allowing the system to use only the common sense knowledge collected from people who fit to the target group's profile. Figure 1 presents an interface of PACO that brings common sense knowledge support. In this interface, teachers should define the learning activity theme and justification. On the right in the interface, it can be seen the common sense support available in this step. As it was discussed in section 3, teachers can use this knowledge in this sub-step to answer the questions that they face with.

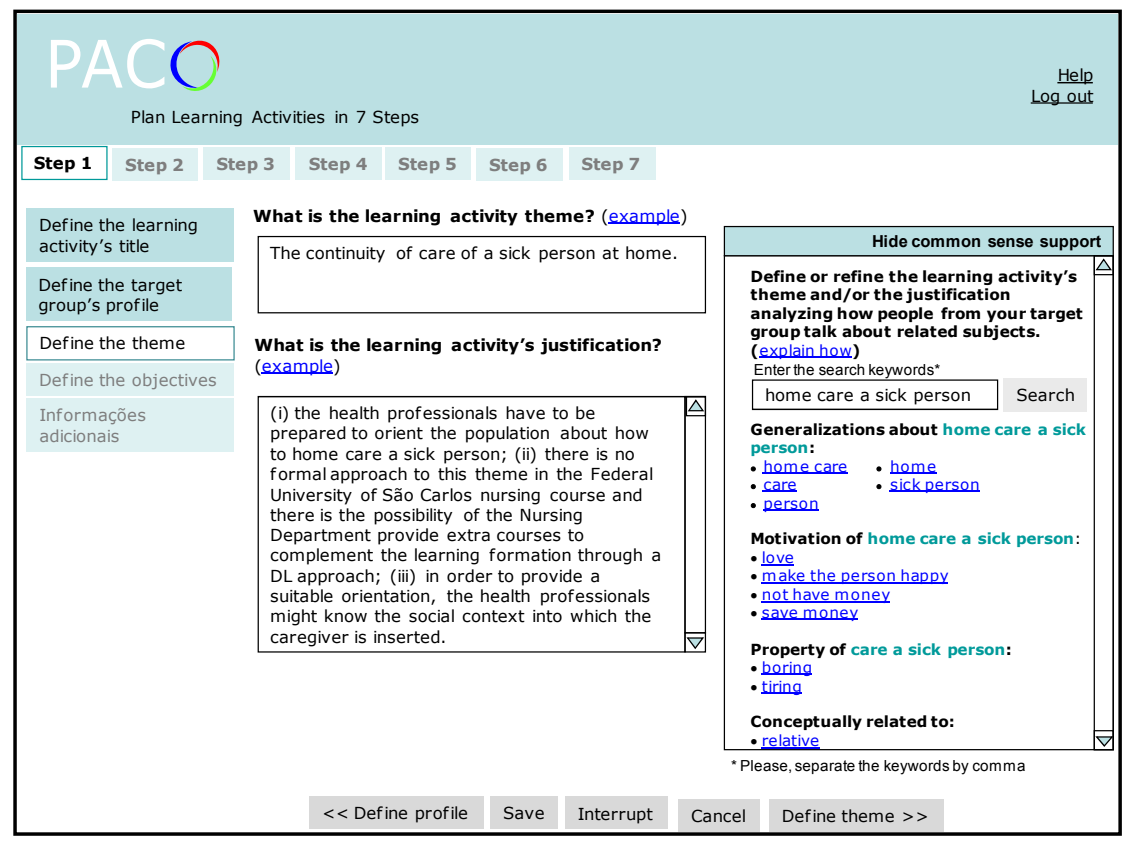

Figure 1. PACO-T Step 1 - Define the theme

In order to analyze how people talk about subjects of interest, teachers have to provide some keywords in the search text field and click on the button "Search". Doing that, the system retrieves the context related to the keywords provided and presents the related common sense knowledge expressed in the ConceptNet in the common sense support box.

The common sense support box is always presented when there is the possibility of teachers to decide something based on this kind of knowledge. By following the steps of the computational representation of PACO, answering the questions presented in each step and exploring the available common sense knowledge, teachers can plan their learning activities taking into account pedagogical issues and fit it to their target group needs. It is worth pointing out that teachers can go back to steps that they have already passed, modify their answers, interrupt a planning and resume it in another moment or even cancel a planning already started. At the end, teachers can export the learning activity plan to text format so that they can print it. 


\section{Conclusions and Future works}

This paper has presented PACO-T, a computational tool to support PACO, a framework to plan learning activities following pedagogical principles. The tool aims to support teachers on planning learning activities, taking into account the seven steps defined in PACO. For that, it was performed a study about what information teachers should provide in each step in order to build up the learning activity plan. Moreover, it was performed a case study which allowed to identify how common sense knowledge can be useful to teachers in order to help them to answer some questions that are inherent in learning activity planning.

With PACO-T, it is intended to make the task of planning learning activities easier for teachers and to give teachers conditions for planning learning activities that fit to their target group's needs and that can promote effective learning. As common sense knowledge expresses cultural knowledge [1], PACO-T allows the planning of culturally contextualized learning activities. As future work, it is proposed to finish implementing PACO-T and to perform other case studies in which learning activities should be planned using the tool in order to assess its usefulness. Furthermore, it is also intended to apply usability tests in the tool.

\section{Acknowledgments}

We thank FAPESP and CAPES for partially support this project.

\section{References}

1. Anacleto, J. C.; Lieberman, H.; Tsutsumi, M.; Neris, V. P. A.; Carvalho, A. F. P.; Espinosa, J.; Zem-Mascarenhas, S.; Godoi, M. S. Can common sense uncover cultural differences in computer applications?. In Artificial Intelligence in Theory and Practice - WCC 2006, vol. 217, Bramer, M. (Ed). Berlin: Springer-Verlag, 2006. p. 1-10.

2.Anacleto, J. C.; Godoi, M. S.; Carvalho, A. F. P. de; Lieberman, H. L. A Common SenseBased On-line Assistant for Training Employees. In: Proc. INTERACT 2007, Rio de Janeiro - Brazil. Heidelberg: Spring-Verlag, LNCS 4662, 2007, p. 243-255.

3.Ausubel, D.P. Psicología educativa: un punto de vista cognoscitivo. Mexico: Editorial Trillas, 1976. /in Spanish/

4.Carvalho, A. F. P. de; Anacleto, J. C.; Zem-Mascarenhas, S. Planning Learning Activities Pedagogically Suitable by Using Common Sense Knowledge. In: Proc of the $16^{\text {th }}$ International Conference on Computing, 2007, Mexico City - Mexico. p. 1-6.

5.Carvalho, A. F. P. de; Anacleto, J. C.; Zem-Mascarenhas, S. . Learning Activities on Health Care Supported by Common Sense Knowledge. In: Proc. of $23^{\text {rd }} S A C, 2008$, Fortaleza Brazil. New York: ACM Press, 2008 p. 1385-1389.

6.Freire, P. Pedagogia da autonomia: saberes necessários à prática educativa. 31 ed. São Paulo: Paz e Terra, 1996. /in Portuguese/

7.Liu, H.; Singh P. ConceptNet: a practical commonsense reasoning toolkit. BT Technology Journal, v. 22, n. 4, p. 211-226, 2004.

8. Neris, V. P. A.; Anacleto, J. C; Zem-Mascarenhas, S. Z.; Carvalho, A. F. P. de PACO - A Framework for Planning Learning Activities Supported by Computers. In Proc. of the 18th Brazilian Symposium on Informatics and Education (SBIE 2007), 2007, São Paulo - Brazil. Porto Alegre: SBC, 2007. p. 597-606. 